\title{
CRISE DE REPRESENTATIVIDADE NO BRASIL: POLITIZAÇÃO OU DESPOLITIZAÇÃO. UMA LEITURA PÓS-JORNADAS DE JUNHO DE 2013
}

\section{REPRESENTATION OF CRISIS IN BRAZIL: OR POLITICIZATION DEPOLITICIZATION. READING POST- DAYS JUNE 2013}

\author{
Gualterberg Nogueira de Lima Silva ${ }^{1}$ \\ Randal Magnani ${ }^{2}$
}

RESUMO: O presente trabalho tem como escopo apresentar à comunidade acadêmica questionamentos sobre a crise de representatividade no Brasil pós-jornadas de junho de 2013, a partir da leitura do direito constitucional. Neste contexto, tem-se como hipótese da presente pesquisa verificar se as jornadas de junho de 2013 acarretaram uma crise de representatividade no Brasil. Para enfrentar o problema mencionado acima, a investigação estabeleceu o seguinte objetivo específico: Se houve (des)politização das jornadas de junho de 2013. Para isso, serão apresentados dados empíricos do Índice de Confiança Social (ICS), do IBOPE Inteligência/2013, que mediu a confiança dos brasileiros nas instituições em geral e nos grupos sociais durante os protestos ocorridos no país em 2013. Assim, do ponto de vista fenomenológico, iremos nos concentrar de como as jornadas de junho de 2013 afetaram o sistema democrático brasileiro.

Palavras chave: Democracia. Liberdade de pensamento. Manifestações Populares. Representação política.

\begin{abstract}
This work has the objective to present the academic community questions about the crisis of representation after the days of june 2013, from a historic perspective in Pietro Castro. In this context, we have a hypothesis of this study: verifying that the days of June 2013 led to a crisis of representation in Brazil. To answer the problem mentioned above, the investigation established the following specific objective: If there was (de) politicization of June 2013 journeys? The empirical dates will be presented the Social Confidence Index ( ICS )from the IBOPE Intelligence / 2013 which measured the confidence of Brazilian institutions in general and in social groups during the protests in the country in 2013. Thus, the phenomenological point of view, we will focus on how the days of June 2013 affected the Brazilian democratic system.
\end{abstract}

Keywords: Democracy. Freedom of thought. Popular demonstrations. Political representation.

\footnotetext{
${ }^{1}$ Mestre em Direito pela Universidade La Salle - Canoas (RS). Pós-graduado em Direito do Estado pela Universidade Federal do Rio Grande do Sul. Professor da Cadeira de Direito da Academia Militar das Agulhas Negras (AMAN) - Resende (RJ). E-mail: gualterberglima@gmail.com

2 Mestre em Direito pelo Centro Universitário Salesiano de São Paulo (UNISAL) - Lorena (SP). Mestre em Ciências Militares pela Escola de Aperfeiçoamento de Oficiais - Rio de Janeiro (RJ). Professor do Curso de Direito da Universidade Estácio de Sá - Campus Resende (RJ). Professor da Cadeira de Direito da Academia Militar das Agulhas Negras (AMAN) - Resende (RJ). E-mail: randalmagnani@ yahoo.com.br
} 
Sumário: 1. Introdução. 2. Momento histórico: as manifestações populares de 2013 no Brasil. 3. Politização do não-político. 4. Minirreforma no sistema político. 5. Conclusão. 6. Referências.

\section{INTRODUÇÃO}

O presente trabalho tem como escopo apresentar à comunidade acadêmica questionamentos sobre a crise de representatividade no Brasil pós-jornadas de junho de 2013, a partir da leitura do direito constitucional.

A partir de então, é possível perceber como as jornadas de junho de 2013 - no sentido de perscrutador da sociedade, afetaram as estruturas de representatividades políticas, de modo a gerar instabilidade no meio político e reorientar uma nova voz na democracia brasileira - os jovens estudantes.

Neste contexto, tem-se como hipótese da presente pesquisa verificar se as jornadas de junho de 2013 acarretaram uma crise democrática no Brasil.

Para enfrentar o problema mencionado acima, a investigação estabeleceu os seguintes objetivos específicos: (a) Se houve (des)politização das jornadas de junho de 2013; e (b) Levantar informações e matizes sobre o perfil dos novos ativistas políticos pós-junho de 2013 no Brasil.

Para se compreender e desenvolver uma análise histórica adequada a respeito das Jornadas de Junho de 2013, não bastam diversas teorias ou fragmentos de teorias jurídicas.

Para isso, serão apresentados dados empíricos, a saber: (a) O Índice de Confiança Social (ICS), do IBOPE Inteligência/2013, que mediu a confiança dos brasileiros nas instituições em geral e nos grupos sociais durante os protestos ocorridos no país em 2013; e (b) será apresentada uma análise empírica do perfil dos manifestantes nas jornadas de junho de 2013 no Brasil.

Rev. de Teorias da Democracia e Direitos Políticos | e-ISSN: 2525-9660 | Goiânia| v. 5 | n. 1 | p. 20-40| Jan/Jun. 2019 
Gualterberg Nogueira de Lima Silva \& Randal Magnani

Tendo em vista a imensa complexidade do fenômeno estudado (jornadas de junho de 2013 e crise de representatividade), este estudo não pretende esgotar o tema.

Do ponto de vista fenomenológico, concentrar-se-á na análise de como as jornadas de junho de 2013 afetaram a participação política no Estado Democrático Brasileiro.

\section{Momento histórico: as manifestações populares de 2013 no Brasil}

As manifestações populares ocorridas no Brasil, no ano de 2013, marcaram um novo cenário histórico, devido a sua originalidade quanto à diversidade ideológica, a multiplicidade de interesses dos diversos grupos sociais participantes e um movimento de bandeira antipartidarista3.

Esta onda de indignação que tomou as ruas das principais capitais brasileiras teve como "pano de fundo" as mudanças vividas pela sociedade brasileira nas últimas décadas. A classe média cresceu e com ela as demandas dos cidadãos por melhores serviços públicos ganharam força 4 .

A fim de inferir este momomento histório, Pietro Costa alerta que a historiografia não é a descrição de coisas ou estados de coisas, mas atribuição de sentido: portanto interpretação, e acrescenta que "o historiador do direito, como qualquer outro historiador, se encontra simplesmente frente a diferentíssimos tipos de texto: o problema comum, ao historiador do direito como a qualquer outro historiador, é compreender que coisa diz o texto e como o texto diz aquilo que diz" (COSTA, 2010, p. 24).

\footnotetext{
${ }^{3}$ Para maiores informações a respeito do assunto: SANTOS, Boaventura de Sousa. Os protestos podem voltar mais fortes e incontroláveis. Disponível em: <http://www.dw.de/protestos-podem-voltar-mais-fortes-eincontrol\%C3\%A1veis-diz-soci\%C3\%B3logo/a-16938502>. Acesso em: 10 mar. 2019.

${ }^{4}$ A corroborar com esse entendimento: Pesquisa de Orçamentos Familiares/POF(2008-2009), do Instituto Brasileiro de Geografia e Estatística/IBGE, que visou mensurar as estruturas de consumo, dos gastos, dos rendimentos e parte da variação patrimonial das famílias brasileiras. Possibilita traçar, portanto, um perfil das condições de vida da população a partir da análise de seus orçamentos domésticos. Disponível em: <www.ibge.gov.br/home/estatistica/populacao/condicaodevida/pof/2008_2009/POFpublicacao.pdf>. Acesso em: 10 mar. 2019.
}

Rev. de Teorias da Democracia e Direitos Políticos | e-ISSN: 2525-9660 | Goiânia| v. 5 | n. 1 | p.20-40| Jan/Jun. 2019 


\section{CRISE DE REPRESENTATIVIDADE NO BRASIL: POLITIZAÇÃO OU DESPOLITIZAÇÃO. UMA LEITURA PÓS-JORNADAS DE JUNHO DE 2013}

Na obra "As Regras do Método Sociológico", Émile Durkheim (1984, p.11) estabeleceu sua metodologia de análise e definiu o fato social como objeto de estudo da sociologia, ressaltando o papel dessa ciência na sociedade contemporânea e na relação entre indivíduo e sociedade.

Entende que a consciência coletiva se forma fora do indivíduo, possuindo poder de coagir as consequências individuais.

Neste sentido, é significativa a noção do fato social (consciência coletiva) elaborada por Durkheim:

É fato social toda maneira de agir, fixa ou não, suscetível de exercer sobre o individuo uma coerção exterior; ou então ainda, que é igual na extensão de uma sociedade dada, aparentando uma existência própria, independente das manifestações individuais que possa ter (DURKHEIM, 1984, p.11).

Existem diversas formas de se determinar um fato social, e uma delas é por meio da análise empírica.

O fato social, conforme Emile Durkheim, deve representar "um certo estado de espírito coletivo".

Algo muito frequente nas sociedades modernas são as pesquisas de opinião pública, feitas com o intuito de averiguar o grau de aprovação de políticas sociais de um governo (legitimidade) num determinado momento histórico.

Com o objetivo de levantar informações sobre a diversidade de matizes ideológicas e o perfil dos participantes das manifestações que aconteceram no Brasil, o IBOPE Inteligência ${ }^{5}$ ouviu 2002 (duas mil e duas) pessoas em oito capitais brasileiras durante os protestos de junho de 2013.

Nesta pesquisa, a maioria dos manifestantes dizia não se sentir representada por partido (89\%) ou político brasileiro (83\%). Entre os entrevistados, 96\% alegaram não ser

\footnotetext{
${ }^{5}$ CNT-IBOPE INTELIGÊNCIA. Pesquisa de Opinião Pública sobre as manifestações: JOB0948/2013BRASIL. Disponível em: http://www.ibope.com.br/pt-br/noticias/Documents/JOB_0948_BRASIL\%20\%20Relatorio\%20de\%20tabelas.pdf. Acesso em: 12 mar. 2019.
}

Rev. de Teorias da Democracia e Direitos Políticos | e-ISSN: 2525-9660 | Goiânia| v. 5 | n. 1 | p. 20-40| Jan/Jun. 2019 
Gualterberg Nogueira de Lima Silva \& Randal Magnani

filiados a nenhum partido político e $86 \%$ não eram filiados a nenhum sindicato, entidade de classe ou entidade estudantil.

Quando questionados sobre quais as reivindicações que os levaram às ruas, 38\% dos entrevistados apontaram a questão do transporte público como primeiro motivo de mobilização.

Quando considerada a soma de todas as questões mencionadas pelos manifestantes, $65 \%$ reivindicavam mudanças no atual ambiente político, $54 \%$ no transporte público e $37 \%$ na área da saúde.

Entre 11 e 15 de julho de 2013, a confiança dos brasileiros nas instituições em geral e nos grupos sociais foi avaliado pelo Índice de Confiança Social (ICS) ${ }^{6}$, medido pelo IBOPE Inteligência, refletindo o momento de protestos e críticas que ocorreram pelo país no ano de 2013.

As 18 (dezoito) instituições avaliadas no ICS buscaram representar diferentes setores da sociedade brasileira, tanto das esferas pública e privada, como da sociedade civil, e os resultados revelaram queda na confiança em relação a todas elas.

A Tabela 1 demonstra o grau de confiança dos brasileiros nas instituições em geral, no período de 2009 a 2013.

Tabela 1: Índice de Confiança Social - 0 a $100(\text { ICS })^{7}$

\footnotetext{
${ }^{6}$ O Índice de Confiança Social (ICS) ouviu 2.002 pessoas com mais de 16 anos em 140 municípios. A pesquisa foi realizada entre 11 e 15 de julho de 2013 pelo IBOPE Inteligência. Disponível em: http://www.ibope.com.br/pt-br/noticias/Paginas/Cai-a-confianca-dos-brasileiros-nas-instituicoes-.aspx; Acesso em: 12 mar. 2019.

${ }^{7}$ O Índice de Confiança Social (ICS) ouviu 2.002 pessoas com mais de 16 anos em 140 municípios. A pesquisa foi realizada entre 11 e 15 de julho de 2013 pelo IBOPE Inteligência. Disponível em: http://www.ibope.com.br/pt-br/noticias/Paginas/Cai-a-confianca-dos-brasileiros-nas-instituicoes-.aspx; Acesso em: 10 mar. 2016.
}

Rev. de Teorias da Democracia e Direitos Políticos | e-ISSN: 2525-9660 | Goiânia| v. 5 | n. 1 | p.20-40| Jan/Jun. 2019 
CRISE DE REPRESENTATIVIDADE NO BRASIL: POLITIZAÇÃO OU DESPOLITIZAÇÃO. UMA LEITURA PÓS-JORNADAS DE JUNHO DE 2013

\begin{tabular}{|c|c|c|c|c|c|}
\hline & 2009 & 2010 & 2011 & 2012 & 2013 \\
\hline - Família & 90 & 91 & 90 & 91 & 90 \\
\hline -Amigos & 67 & 69 & 68 & 70 & 67 \\
\hline - Brasileiros de um modo geral & 59 & 60 & 60 & 59 & 56 \\
\hline - Vizinhos & 59 & 59 & 59 & 61 & 57 \\
\hline - Corpo de bombeiros & 88 & 85 & 86 & 83 & 77 \\
\hline - Igrejas & 76 & 73 & 72 & 71 & 66 \\
\hline - Forças armadas & 71 & 69 & 72 & 71 & 64 \\
\hline - Meios de comunicação & 71 & 67 & 65 & 62 & 56 \\
\hline - Empresas & 61 & 60 & 59 & 57 & 51 \\
\hline - Organizações Civis & 61 & 61 & 59 & 57 & 49 \\
\hline - Polícia & 52 & 52 & 55 & 54 & 48 \\
\hline - Bancos & 61 & 58 & 57 & 56 & 48 \\
\hline - Escolas públicas & 62 & 60 & 55 & 55 & 47 \\
\hline - Poder judiciário/ Justiça & 52 & 53 & 49 & 53 & 46 \\
\hline - Presidente da República & 66 & 69 & 60 & 63 & 42 \\
\hline - Governo Federal & 53 & 59 & 53 & 53 & 41 \\
\hline - Eleições/ Sistema eleitoral & 49 & 56 & 52 & 47 & 41 \\
\hline - Governo do seu município & 53 & 50 & 47 & 45 & 41 \\
\hline - Sindicatos & 46 & 44 & 44 & 44 & 37 \\
\hline - Sistema Público de saúde & 49 & 47 & 41 & 42 & 32 \\
\hline - Congresso nacional & 35 & 38 & 35 & 36 & 29 \\
\hline - Partidos Políticos & 31 & 33 & 28 & 29 & 25 \\
\hline GERAL & 60 & 60 & 58 & 57 & 50 \\
\hline
\end{tabular}

Fonte: IBOPE Inteligência (2013)

Nesta esteira, um fenômeno social marcou os novos movimentos sociais (e as jornadas de junho de 2013 no Brasil): o ceticismo em relação às instituições partidárias.

Antes de analisar este novo fenômeno social, cabe recuperar as reflexões de Pietro Costa sobre a dimensão hermenêutica da historiografia, pois esta se utiliza claramente da inscrição da pesquisa no horizonte teórico escolhido, e alerta o autor:

Rev. de Teorias da Democracia e Direitos Políticos | e-ISSN: 2525-9660 | Goiânia| v. 5 | n. 1 | p. 20-40| Jan/Jun. 2019 
Nesta moldura de algum modo tranqüilizadora realizava-se, é claro, a aventura da pesquisa "de campo", cujos resultados não podiam ser, na realidade, rigidamente predeterminados (no conteúdo e na qualidade) pelos "pré-juízos" que a cada vez eram compartilhados: não importa quais fossem os resultados da pesquisa concreta, o método, o objeto e, em resumo, a identidade da historiografia eram dados claramente pela inscrição da pesquisa no horizonte teórico escolhido. A historiografia trazia a sua legitimação teórica do fato de ser concebida como um capítulo daquilo que chamaria de uma "grande narrativa": um discurso global sobre o homem e as suas relações intersubjetivas. É nisso que a historiografia encontrava a sua colocação, a sua destinação de sentido, contribuindo para o seu desenvolvimento e ao mesmo tempo dependendo disso (COSTA, 2010, p. 17).

Em relação ao ceticismo das instituições partidárias, essa ideia é perfeitamente internalizada por Canotilho, ao aduzir que "parece, porém, ser razoavelmente correcto afirmar-se que os fenómenos de ‘rejeição`, de ‘indiferença’, de ‘insatisfação`, perante os esquemas clássicos de manifestação política - eleições e partidos - estão ligados a sugestões de mudanças institucionais e a novos apelos a formas de democracia directa" (CANOTILHO, 2006, p. 313).

Neste contexto social, seria o homem um zoon politikon ${ }^{8}$ ?

Pietro Costa discorda deste termo, pois "apenas as abelhas ou as formigas realizam a imagem aristotélica do zoon politikòn, mas não o ser humano, dominado pela necessidade e pela busca por poder, sempre inclinado à competição e ao conflito" (COSTA, 2010, p. 134).

Da mesma linha de observação, Hannah Arendt acrescenta que "como se no homem houvesse algo político que pertencesse à sua essência - conceito que não procede; o homem é a-político. A política surge no entre-os-homens; portanto totalmente fora dos homens. Por conseguinte, não existe nenhuma substância política original. A política surge no intra-espaço e se estabelece como relação. Hobbes compreendeu isso"(ARENDT, 2004, p. 21).

\footnotetext{
${ }^{8}$ Zoon politikon (grego) termo utilizado por Aristóteles que dizia que o homem normal é um animal (zoon) político (politikon)- um ser racional que fala e pensa (zoon logikon), em sua interação necessária na cidadeEstado (pólis), assim "é evidente, pois, que a cidade faz parte das coisas da natureza, que o homem é naturalmente um animal político, destinado a viver em sociedade, e que aquele que, por instinto, e não porque qualquer circunstância o inibe, deixa de fazer parte de uma cidade, é um ser vil ou superior ao homem." $c f$. ARISTÓTELES. A política. Trad. de Nestor Silveira Chaves. Rio de Janeiro: Ediouro, 1997, p. 13.
}

Rev. de Teorias da Democracia e Direitos Políticos | e-ISSN: 2525-9660 | Goiânia| v. 5 | n. 1 | p.20-40| Jan/Jun. 2019 


\section{CRISE DE REPRESENTATIVIDADE NO BRASIL: POLITIZAÇÃO OU DESPOLITIZAÇÃO. UMA LEITURA PÓS-JORNADAS DE JUNHO DE 2013}

A partir de então, é possível perceber que "o voto é a expressão (visível e formalizada) do consenso do qual se pretende fazer depender a legitimidade do poder; o voto é o instrumento que permite aos representados reconhecer os 'seus' representantes (de reconhecer-se neles); o voto é, por fim, o exercício de um poder que incide (ainda que com modalidades e intensidades diversas) na seleção da elite política" (COSTA, 2010, p. 171).

Em última análise, as referidas pesquisas empíricas do IBOPE Inteligência sobre as Jornadas de Junho de 2013 refletem problemas de legitimidade política da autoridade em todas as esferas do Poder Político.

Nas palavras de Gohn (2004, p. 341), estes novos ativistas políticos querem manifestar mais seus "sentimentos" do que viver segundo as diretrizes preconizadas por alguma "teoria, partido ou instituição de planejamento".

A partir de então, é possível perceber que "neste cenário, acrescente-se que a produção latino-americana sobre os movimentos sociais muitas vezes esteve bastante permeada por pressupostos ideológicos que derivavam de matrizes político-pragmáticas de partidos políticos. Isto ocorreu porque certos movimentos sociais do final dos anos 70 e início dos 80 eram expressões políticas de forças políticas nacionais" (GOHN, 2004, p. 216).

Em meio a essas reflexões, pode-se dizer que as manifestações populares ocorridas no Brasil em junho de 2013 representam um novo paradigma na história da democracia brasileira9"; ou dito em outras palavras: o eleitor brasileiro "descobriu" que é contribuinte (e o contribuinte "descobriu" que é eleitor), constituindo-se no mesmo "ser" que possui direitos e obrigações, chamado cidadão.

\section{Politização do não-político}

\footnotetext{
${ }^{9}$ Por que do uso das teorias europeias e do caráter mais empírico da maioria dos primeiros trabalhos latinoamericanos sobre os movimentos sociais? "A influência teórica europeia inicial se fez predominantemente por meio do paradigma marxista, e isto também se explica pela predominância deste paradigma nos meios acadêmicos, principalmente nas universidades públicas e nas chamadas comunitárias, nos anos 70; e pelos projetos concretos de luta para a redemocratização naquele período, elaborados pela esquerda a partir de leituras gramsciana", $c f$. GOHN, Maria da Glória Marcondes. Teorias dos movimentos sociais: paradigmas clássicos e contemporâneos. 4. ed. São Paulo: Loyola, 2004, p. 216.
}

Rev. de Teorias da Democracia e Direitos Políticos | e-ISSN: 2525-9660 | Goiânia| v. 5 | n. 1 | p. 20-40| Jan/Jun. 2019 
Para explicar e contextualizar o "processo de politização da sociedade", Canotilho elenca dois modelos:

\begin{abstract}
Ou entendemos a sociedade como um conjunto de sistemas funcionalmente diferenciados (o sistema político, o sistema econômico, o sistema de investigação, etc) ou compreendemos a sociedade como uma sociedade marcadamente política. No primeiro modelo, a democracia é a forma de autodescrição do sistema político, é a forma em que o sistema político se organiza a si próprio. No segundo modelo, a sociedade é uma sociedade fundamentalmente politizada porque nela tudo é política, tudo é concebível como conflito de interesses carecido de decisão, tudo é politicamente aberto, tudo permite a qualquer indivíduo a inclusão política (CANOTILHO, 2006, p. 317).
\end{abstract}

No que diz respeito à história da representatividade política, Pietro Costa comenta que "a representação, assim entendida, evoca primariamente um ser e, secundariamente, um agir: podemos falar da representação como um 'ser para' (ou 'no lugar de') um sujeito ausente e/ou como um 'agir por' (ou 'no lugar de') um sujeito inativo" (COSTA, 2010, p. 155).

Algo muito frequente nas sociedades modernas são as pesquisas de opinião pública, feitas com o intuito de averiguar o grau de aprovação social de um governo (legitimidade).

No que concerne à participação política dos cidadãos, Pietro Costa alerta que:

É o Estado que atribui, aos sujeitos e a si mesmo (mais precisamente a alguns dos seus órgãos), direitos e obrigações; logo, é o Estado que pode decidir pelo favorecimento da participação política dos cidadãos atribuindo a eles, para este fim, os direitos que tornam isso possível: os direitos políticos. O Estado moderno é um Estado representativo não porque desce a fazer pactos com os sujeitos, sofrendo a iniciativa dos sujeitos, renunciando à sua absoluta supremacia, mas porque escolhe, em perfeita autonomia, de organizar-se confiando aos cidadãos o papel de designar (através do mecanismo eleitoral) os componentes de uma determinada instituição sua (COSTA, 2010, p. 186).

Da mesma linha de observação:

Rev. de Teorias da Democracia e Direitos Políticos | e-ISSN: 2525-9660 | Goiânia| v. 5 | n. 1 | p.20-40| Jan/Jun. 2019 


\title{
CRISE DE REPRESENTATIVIDADE NO BRASIL: POLITIZAÇÃO OU DESPOLITIZAÇÃO. UMA LEITURA PÓS-JORNADAS DE JUNHO DE 2013
}

\begin{abstract}
O voto é a expressão (visível e formalizada) do consenso do qual se pretende fazer depender a legitimidade do poder; o voto é o instrumento que permite aos representados reconhecer os 'seus' representantes (de reconhecer-se neles); o voto é, por fim, o exercício de um poder que incide (ainda que com modalidades e intensidades diversas) na seleção da elite política (COSTA, 2010, p. 172).
\end{abstract}

Em meio a essas reflexões, cabe repelir uma suposta paralisia da vontade política da população.

Em relação ao ceticismo das instituições partidárias e uma "presumida despolitização" dos manifestantes de junho de 2013, cabe destacar os ensinamentos de Georges Burdeau , na obra "O Estado":

\begin{abstract}
A política já não ter muito sucesso enquanto atividade belicosa, é provado pelo fenômeno que se qualificou de despolitização. Por certo sabe-se que essa expressão é equívoca, mas, em todo caso, designa uma realidade na medida em que traduz o desapego dos governados para com lutas partidárias. A atividade política não está desvalorizada, mas há transferência de seus objetivos para movimentos que antes lhe permaneciam alheios. Trate-se das organizações profissionais, das associações de lazer, dos grupos de moradores nos grandes conjuntos, etc., a política se manifesta com a preocupação com o possível e a vontade de obter resultados; ou seja, no espírito de gestão (BURDEAU, 2005, p. 97).
\end{abstract}

Em primeiro lugar, aqui como noutros quadrantes territoriais, os impulsos a favor de mudanças em relação ao sistema político derivam mais da "insatisfação" relativamente à condução da política pelas elites partidárias do que da convicção cívica em torno da participação nos assuntos governamentais da nação.

Canotilho (2006, p. 318), em estudo sobre democracia participativa, realiza duas perquirições sobre os novos ativistas políticos, a saber:

(1) “Quem dinamiza e 'suporta' a movimentação participativa?”; e

(2) “Os setores populacionais 'descontentes', mas com fraca formação e educação e sobretudo, com diminuto interesse pela política; ou as cidadãs e os cidadãos com 'interesse permanente', formação sólida experimentada e conhecimentos das regras de direção política?"

A respeito deste ponto, para o constitucionalista português, necessitamos entender o significado da "estratificação social da participação".

Rev. de Teorias da Democracia e Direitos Políticos | e-ISSN: 2525-9660 | Goiânia| v. 5 | n. 1 | p. 20-40| Jan/Jun. 2019 
Segundo Canotilho (2006, p. 318), estudos feitos em alguns países parecem demonstrar que o "recrutamento" de ativistas políticos nos movimentos de democracia direta incide sobre "estratos privilegiados" da população porque os agentes políticos recrutados prosseguem estratégias racionais de êxito pessoal e coletivo.

Paradigma a respeito de "estrato privilegiado" ocorreu em Portugal sobre a questão do aborto e a regionalização (CANOTILHO, 2006, p. 318).

A partir de então, é possível perceber que o exercício da atividade política (ou para os constitucionalistas - cidadania) sempre existiu na sociedade. Ela é inerente à sociedade. $\mathrm{O}$ que houve nos movimentos populares de junho de 2013 foi um descrédito em relação às instituições partidárias.

\title{
4 Minirreforma no sistema político
}

As manifestações que tomaram as ruas das principais capitais brasileiras em 2013 apresentaram diversas pautas, como a reforma política.

Nesse sentido, Pietro Costa traz a seguinte observação:

\begin{abstract}
A democracia dos modernos pressupõe uma nova antropologia política, uma nova visão do ser humano e de sua relação com a ordem política; pressupõe aquele protagonismo do sujeito que, por vias diversas, alcança e compromete a inteira cultura político-jurídica dos séculos XVII e XVIII. Se quisermos ir até a raiz do fenômeno e obter in statu nascenti a imagem moderna da democracia, convém, porém, pensar não no problema da forma de governo, mas no processo de fundação da ordem política como tal: é a esta altura que a antropologia individualística se encontra com o tema da democracia, renovando-o desde as raízes (COSTA, 2010, p. 240).
\end{abstract}

Em meio a essas reflexões, a intenção da mobilização das jornadas de junho de 2013 era demonstrar o desejo popular por mudanças no sistema político.

Rev. de Teorias da Democracia e Direitos Políticos | e-ISSN: 2525-9660 | Goiânia| v. 5 | n. 1 | p.20-40| Jan/Jun. 2019 


\section{CRISE DE REPRESENTATIVIDADE NO BRASIL: POLITIZAÇÃO OU DESPOLITIZAÇÃO. UMA LEITURA PÓS-JORNADAS DE JUNHO DE 2013}

Em resposta, o Poder Executivo Federa ${ }^{10}$ propôs um plebiscito com intuito de verificar se a população desejava ou não a convocação de uma Assembleia Constituinte exclusiva para realizar a reforma política.

O processo constituinte seria específico para estabelecer novas regras no sistema político como mudanças na forma de escolha de governantes e parlamentares, financiamento de campanhas eleitorais, coligações entre partidos, propaganda na TV e no rádio e outros pontos.

No entanto, a proposta de convocação de uma Assembleia Constituinte exclusiva para realizar a reforma política enfrentou resistências e não foi aprovada em tempo hábil para que pudesse valer já para as eleições de 2014.

Algumas propostas de reforma política foram apresentadas nos últimos anos no Congresso Nacional ${ }^{11}$, como:

a) financiamento público exclusivo de campanha;

b) fim das coligações, porém permitindo que partidos façam federações partidárias que durariam, no mínimo, quatro anos;

c) coincidência temporal das eleições (municipais, estaduais e federais);

d) ampliação da participação da sociedade na apresentação de projetos de iniciativa popular, inclusive via internet; $\mathrm{e}$

e) fim do sistema de lista aberta partidária.

Pietro Costa comenta que:

Resta certo, como último baluarte da lógica democrática, o sistema representativo. Põe-se, todavia, um segundo problema: se é possível creditar ao procedimento representativo aquele valor participativo tradicionalmente a ele atribuído ou, melhor, se a dimensão da participação foi posta a perigo pela erosão da autonomia decisional

\footnotetext{
${ }^{10}$ Discurso da Presidente da República, Dilma Rousseff, durante reunião com governadores e prefeitos de capitais, realizado em 24 de junho de 2013. Disponível em: <http://www2.planalto.gov.br/acompanhe-oplanalto/discursos/discursos-da-presidenta/discurso-da-presidenta-da-republica-dilma-rousseff-durante-reuniaocom-governadores-e-prefeitos-de-capitais>. Acesso em: 12 mar. 2019.

${ }^{11}$ Informação da Câmara dos Deputados. Disponível em: <http://www2.camara.leg.br/>. Acesso em: 12 mar. 2019.
}

Rev. de Teorias da Democracia e Direitos Políticos | e-ISSN: 2525-9660 | Goiânia| v. 5 | n. 1 | p. 20-40| Jan/Jun. 2019 
Gualterberg Nogueira de Lima Silva \& Randal Magnani

dos sujeitos, pela incidência dos meios de comunicação de massa e, enfim, pelo caráter autorreferencial do sistema político (COSTA, 2010, p.247).

Fica evidente que, no caso brasileiro, os protestos de 2013 tiveram o papel extremamente positivo de estrugir o sistema político e colocar em debate práticas consolidadas que deformam e desmoralizam a democracia brasileira.

Em meio a essas reflexões, a partir do mês de junho de 2013, passaram a ocorrer manifestações de repúdio à presença de bandeiras de partidos políticos nas manifestações. Destarte, a rejeição à presença de bandeiras partidárias pode ser analisada como crítica aos tradicionais instrumentos de organização coletiva ou despolitização.

Da mesma linha de observação, a onda de protestos de 2013 mobilizou o debate no país e levantou um amálgama de questionamentos sobre objetivos, rumos, pautas e significados de um movimento popular singular na história brasileira desde a restauração do regime democrático em 1985.

E esse modelo horizontalizado e apartidário destacou-se como principal herança do papel que as redes sociais assumiram para a organização de atos e também como plataforma para novos "porta-vozes" de demandas difusas.

Além disso, esse fato também resultou em mais de uma forma de identificação na política dos sujeitos-atores que compareceram às ruas em 2013: por um lado, os identificados com movimentos sociais e (ou) partidos políticos; por outro, os participantes individuais, convocados, sobretudo, pelas mídias digitais.

Essas duas formas de ser sujeito político geraram as contradições e os conflitos políticos presentes no processo mobilizatório, o que levou as manifestações às incertezas sobre as possibilidades ou não de novas manifestações em 2014 e (ou) sobre o futuro político dos processos mobilizatórios nas ruas.

Rev. de Teorias da Democracia e Direitos Políticos | e-ISSN: 2525-9660 | Goiânia| v. 5 | n. 1 | p.20-40| Jan/Jun. 2019 


\section{CRISE DE REPRESENTATIVIDADE NO BRASIL: POLITIZAÇÃO OU DESPOLITIZAÇÃO. UMA LEITURA PÓS-JORNADAS DE JUNHO DE 2013}

Em 2013, o Instituto Brasileiro de Geografia e Estatística (IBGE) divulgou a Pesquisa Nacional por Amostra de Domicílios (PNAD/2013) ${ }^{12}$, com os principais indicadores sobre a utilização da Internet e a posse de telefone móvel celular para uso pessoal entre os jovens brasileiros.

A PNAD coletou um conjunto de dados de Tecnologias de Informação e Comunicação (TIC) mais amplo, com foco na internet em banda larga.

O gráfico abaixo demonstra que a proporção de pessoas que utilizavam internet foi crescente conforme aumentava a classe de rendimento mensal domiciliar per capita. Em 2013, o maior percentual $(89,9 \%)$ foi observado na classe de mais de 10 (dez) salários mínimos, enquanto o menor (23,9\%), na classe sem rendimento a $1 \frac{1}{4}$ (um quarto) do salário mínimo.

Conforme Roberto Luís Olinto Ramos (Diretor de Pesquisas/IBGE), a publicação da PNAD/2013 apresenta, inicialmente, uma breve visão da pesquisa, o plano de amostragem, esclarecimentos sobre os indicadores-chave das TIC e uma análise das informações produzidas necessárias para a compreensão desses resultados.

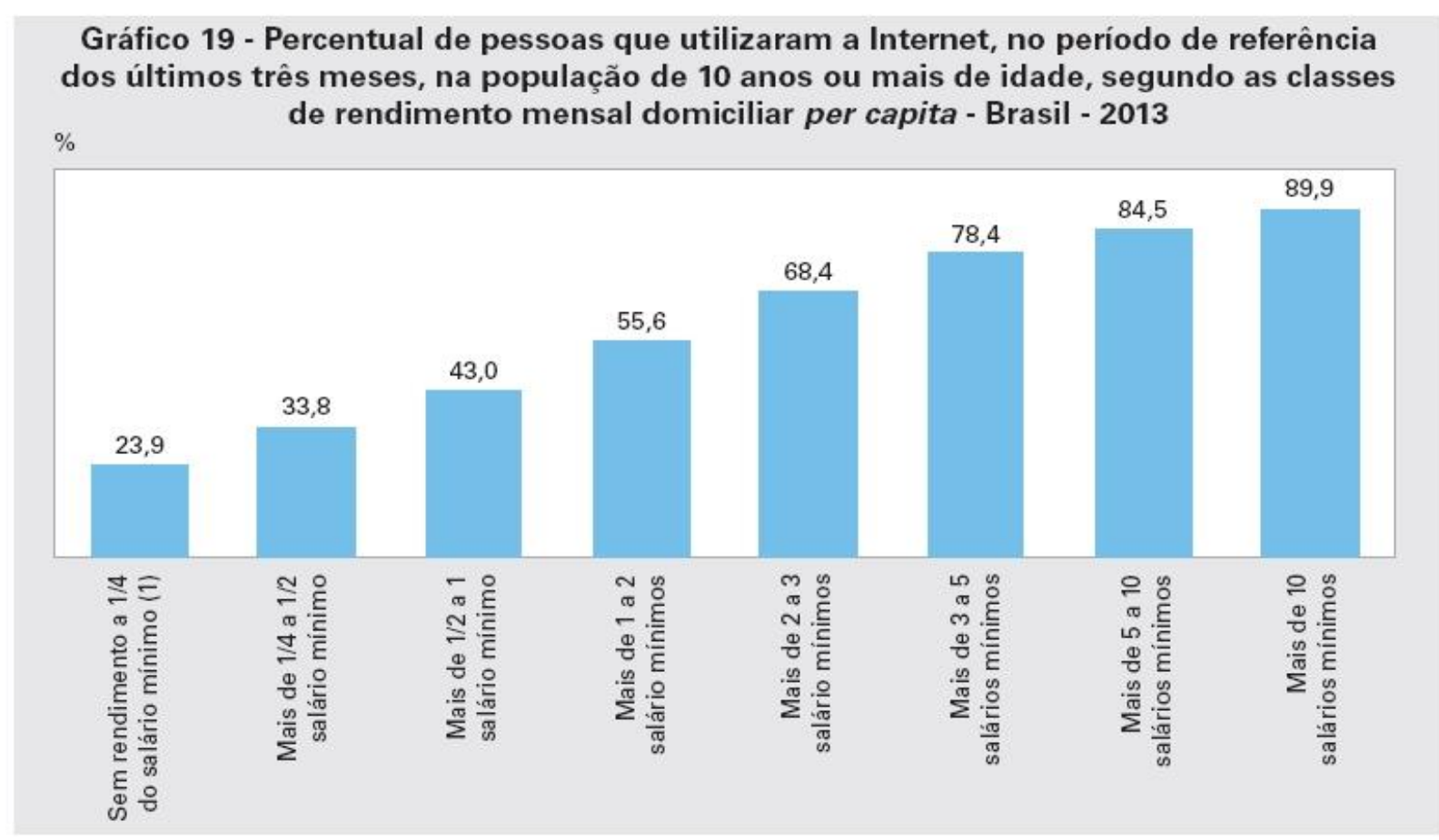

Fonte: IBGE, Diretoria de Pesquisas, Coordenação de Trabalho e Rendimento, Pesquisa Nacional por Amostra de Domicílios 2013.

Nota: Exclusive as pessoas cuja condição na unidade domiciliar era pensionista, empregado doméstico ou parente do empregado doméstico.

(1) Inclusive as pessoas moradoras em unidades domiciliares cujos componentes recebiam somente em benefícios. 
É nesse contexto que cabe recuperar as reflexões de Castells (2003, p. 130) que o uso da internet tende a aprofundar a crise da legitimidade política, ao se pronunciar nos seguintes termos:

\footnotetext{
"Assim, por enquanto, em vez de fortalecer a democracia promovendo o conhecimento e a participação dos cidadãos, o uso da internet tende a aprofundar a crise da legitimidade política ao fornecer uma plataforma de lançamento mais ampla para a política do escândalo. O problema, naturalmente, não está na internet, mas no tipo de política que nossas sociedades estão gerando. Uma política que em última instância molda o poder dos Estados numa época em que eles se defrontam com uma transformação de seu ambiente de segurança" (CASTELLS, 2003, p. 130).
}

Nas democracias ocidentais consolidadas, Manuel Castells mostra como as eleições têm revelado um dado importante: a diminuição da participação da população nos processos eleitorais. Para ele a democracia está em crise e como consequência há uma clara crise de legitimidade, pois “(...) as novas condições institucionais, culturais e tecnológica do exercício democrático, tornaram obsoletos os sistemas partidários existentes, levando à volatilidade eleitoral, o desaparecimento gradativo dos partidos e a importância decisiva da mídia nos processos eleitorais e assim a tendência global parece indicar ou confirmar, ao longo do tempo, a proporção decrescente de votos para os partidos" (CASTELLS, 2003, p. 401).

É preciso acrescentar que a revolução tecnológica recente no campo da informática e das comunicações tem dado a movimentos desse tipo a possibilidade de dispensar as diferentes estruturas partidárias num de seus papéis tradicionais, o da mediação entre representados e seus representantes. Mensagens eletrônicas transmitem em frações de segundo informação, reivindicação, solicitações diversas e até pressões por posicionamentos favoráveis ou contrários do parlamentar. Com isso, eleitores não precisam mais se dirigir à seção local, estadual e nacional do partido sucessivamente, para serem ouvidos por seus representantes.

Rev. de Teorias da Democracia e Direitos Políticos | e-ISSN: 2525-9660 | Goiânia| v. 5 | n. 1 | p.20-40| Jan/Jun. 2019 


\section{CRISE DE REPRESENTATIVIDADE NO BRASIL: POLITIZAÇÃO OU DESPOLITIZAÇÃO. UMA LEITURA PÓS-JORNADAS DE JUNHO DE 2013}

A partir de então, é possível perceber que a internet está contribuindo para aumentar o número de cidadãos que sentados sozinhos à frente de um computador, sem realizar interações sociais, fazem as suas escolhas e fiscalizações independentemente da existência de partido, o que tem influenciado diretamente na taxa de crescimento dos partidos políticos.

Ressalta-se que a inclusão digital no Brasil está diretamente relacionada às questões de infraestrutura e escolaridade, mas quando comparados os fatores, a escolaridade se destaca como o mais decisivo para adesão à rede. Outro ponto importante é a quantidade de jovens que estão cada vez mais conectados e veem no smartphone a principal porta de entrada para o mundo digital, fazendo com que as redes sociais sirvam como "ponto de encontro" para possíveis mobilizações.

Corroborando o fato de que no Brasil, cada vez mais os jovens estão conectados à internet, o gráfico abaixo demonstra o percentual de pessoas que utilizaram a rede mundial de computadores no ano de 2013. Observou-se, na análise por distribuição etária, que os grupos mais jovens registraram os maiores percentuais de utilização, logo, pode-se concluir que o avanço na conectividade em geral foi impulsionado pelo crescimento no porcentual da população com 10 anos ou mais de idade que tinha telefone celular para uso pessoal. 


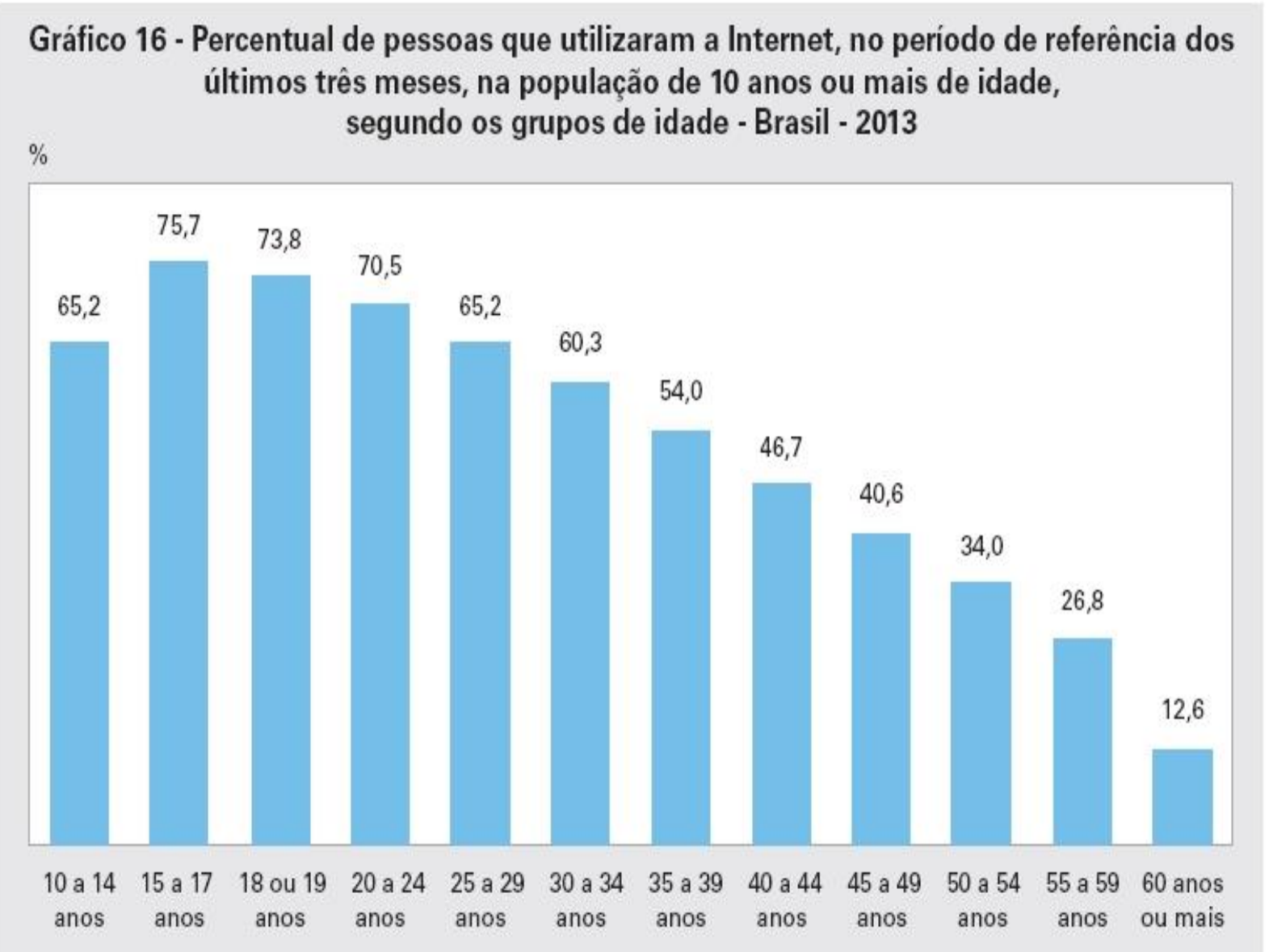

Fonte: IBGE, Diretoria de Pesquisas, Coordenaçăo de Trabalho e Rendimento, Pesquisa Nacional por Amostra de Domicilios 2013.

Por outro lado, a pesquisa também mostra que a segurança on-line das crianças e adolescentes é uma preocupação, pois, por um lado, as crianças e adolescentes estão cada vez mais conectadas, elas estão também cada vez mais expostas a conteúdos mercadológicos na rede. Esse resultado revela a necessidade de difusão e ampliação do debate sobre oportunidades e riscos associados ao uso da internet por iniciativa de políticas públicas.

Embora se aponte as possibilidades do uso da tecnologia para a formação de movimentos da sociedade civil e participação em fóruns eletrônicos de deliberação, há outra

Rev. de Teorias da Democracia e Direitos Políticos | e-ISSN: 2525-9660 | Goiânia| v. 5 | n. 1 | p.20-40| Jan/Jun. 2019 


\section{CRISE DE REPRESENTATIVIDADE NO BRASIL: POLITIZAÇÃO OU DESPOLITIZAÇÃO. UMA LEITURA PÓS-JORNADAS DE JUNHO DE 2013}

realidade no Brasil - o acesso às contas públicas -, promovido pela Lei de Acesso à Informação (Lei $n^{\circ} 12.527 / 11$ ), a qual regulamenta o art. 5², inc. XXXIII, da Constituição Federal de 1988, facilitando o controle e a demanda dos cidadãos por serviços públicos de qualidade.

A prestação de serviços desenvolvida pelo poder público ao cidadão por meio da internet também é uma realidade, uma vez que a maior parte de certidões negativas (eleitorais, policiais, judiciais) tem-se acesso por meio virtual, disponível a qualquer cidadão com conexão banda larga.

Conforme se pode verificar, nos dias atuais a utilização da internet e das redes sociais têm influenciado cada vez mais o dia a dia das pessoas e o fluxo de informações, fato que tem suscitado intensos debates a fim de se verificar a real dimensão dessa nova realidade, diante dos inúmeros desafios que se apresentam.

Desta forma, é possível perceber que houve três legados dessa onda de protestos de 2013: a percepção da sociedade de que sua mobilização pode dar resultado; a capacidade de articulação e de engajamento das pessoas nas redes sociais com aptidão de alcançar as ruas; e a proliferação de diversos grupos e demandas.

\section{Conclusão}

Neste contexto, a presente pesquisa teve como escopo apresentar à comunidade acadêmica questionamentos sobre uma possível despolitização e crise de representatividade no Brasil pós-jornadas de junho de 2013.

Conforme o IBOPE Inteligência que ouviu 2002 (duas mil e duas) pessoas, em oito capitais brasileiras, durante os protestos de junho de 2013. A maioria dos manifestantes dizia não se sentir representada por partido $(89 \%)$ ou político brasileiro (83\%). Entre os entrevistados, $96 \%$ alegaram não ser filiados a nenhum partido político e $86 \%$ não eram filiados a nenhum sindicato, entidade de classe ou entidade estudantil.

Rev. de Teorias da Democracia e Direitos Políticos | e-ISSN: 2525-9660 | Goiânia| v. 5 | n. 1 | p. 20-40| Jan/Jun. 2019 
A partir de então, é possível constatar que as manifestações de 2013 ocorreram independentemente de qualquer chamado de organizações formais, seja da sociedade civil ou do sistema político. Essa foi a grande novidade em relação a outros momentos similares de grandes mobilizações de rua da história brasileira.

Do ponto de vista fenomenológico, as jornadas de junho de 2013 no Brasil (e os novos movimentos sociais) marcaram o ceticismo em relação às instituições partidárias.

Há, sem dúvida, a expressão de um profundo mal-estar que - a propósito das reivindicações de junho de 2013, ganhou uma dimensão pública, não partidária e nacional.

A ação política, aquela com consequências decisivas sobre os rumos da história, continua sendo presencial. Ela é decisiva quando toma as ruas.

Em última análise, as manifestações ocorridas no Brasil em junho de 2013, grande parte delas protagonizadas por jovens estudantes, nasceram para (re)questionar o atual modelo de sistema partidário brasileiro.

Ainda que o presente estudo sobre as jornadas de junho de 2013 tenha chegado a um entendimento, o tema não está esgotado, podendo, num futuro próximo, chegar a outros juízos, diante dos inúmeros desafios em que a democracia se apresenta.

\section{Referências}

BRASIL. Constituição Federal de 1988. Disponível em: <http://www.planalto.gov.br/ccivil_03/constituicao/constituicaocompilado.htm>. Acesso em: 10 mar. 2019.

Instituto Brasileiro de Geografia e Estatística. Pesquisa Nacional por Amostra de Domicílios. Acesso à internet e à televisão e posse de telefone móvel celular para uso pessoal: 2005/2013. Disponível em: 〈http://biblioteca.ibge.gov.br/visualizacao/livros/liv93373.pdf〉. Acesso em: 17 mar. 2019.

Lei $\mathbf{n}^{\mathbf{0}}$ 12.527/11. Regula o acesso a informações previsto no inciso XXXIII do art. $5^{\circ}$, no inciso II do $\S 3^{\circ}$ do art. 37 e no $\S 2^{\circ}$ do art. 216 da Constituição Federal; altera a Lei $n^{\underline{0}}$ 8.112, de 11 de dezembro de 1990; revoga a Lei $\mathrm{n}^{\mathrm{o}}$ 11.111, de 5 de maio de 2005, e

Rev. de Teorias da Democracia e Direitos Políticos | e-ISSN: 2525-9660 | Goiânia| v. 5 | n. 1 | p.20-40| Jan/Jun. 2019 
CRISE DE REPRESENTATIVIDADE NO BRASIL: POLITIZAÇÃO OU DESPOLITIZAÇÃO. UMA LEITURA PÓS-JORNADAS DE JUNHO DE 2013

dispositivos da Lei no $\mathbf{0}$ 8.159, de 8 de janeiro de 1991; e dá outras providências. Disponível em: 〈http://www.planalto.gov.br/ccivil_03/leis/L12527.htm〉. Acesso em: 12 mar. 2019.

BURDEAU, Georges. O Estado. Sao Paulo: Martins Fontes, 2005.

CANOTILHO, José Joaquim Gomes. "Brancosos" e Interconstitucionalidade: itinerários dos discursos sobre historicidade constitucional. Coimbra: Almedina, 2006.

CASTELLS, Manuel. Redes de indignação e esperança. Trad. Carlos Alberto Medeiros. Rio de Janeiro: Zahar, 2003.

COSTA, Pietro. Soberania, Representação e Democracia: ensaios de história do pensamento jurídico. Tradução de A. R. de Castro et al. Curitiba: Juruá, 2010.

DURKHEIM, Émile. As regras do método sociológico. São Paulo: Martins Fontes, 1984.

GOHN, Maria da Glória Marcondes. Teorias dos movimentos sociais: paradigmas clássicos e contemporâneos. 4. ed. São Paulo: Loyola, 2004. 